\title{
Transgresión poética en tiempos de estética posmoderna: La propuesta materialista histórica en Troppo mare, de Javier Egea
}

\author{
Poetic transgression in the postmodern aesthetic period: the historical materialist \\ proposal in Troppo Mare, by Javier Egea
}

\author{
Fernando Candón Ríos \\ fernando.candon.rios@gmail.com \\ Grupo de Estudios de Literatura Española \\ Contemporánea (HUM-330). Universidad de \\ Valladolid, España
}

Recepción: 12 Agosto 2019

Aprobación: 10 Mayo 2020

Publicación: 15 Mayo 2020

Cita sugerida: Candón Ríos, F. (2020). Transgresión poética en tiempos de estética posmoderna: La propuesta materialista histórica en Troppo mare, de Javier Egea. Olivar, 20(31), e073.https://doi.org/10.24215/18524478e073

\begin{abstract}
Resumen: El presente artículo realiza una aproximación a Troppo mare (1984), de Javier Egea, a través del análisis estético e ideológico del poema como objeto verbal estético. La importancia del contexto histórico y del propio contenido textual se encuentran entrelazados debido a que Egea escribe dicha obra en 1980 como alegato poético al materialismo histórico, pero no se publica hasta 1984 , en pleno auge de la posmodernidad en España. Por tanto, el poema, de carácter marxista, se encuentra en el momento de su publicación con un problema de recepción debido a la rápida transformación social y política que se vive durante los años de la Transición española.

Palabras clave: Poesía, Materialismo histórico, Javier Egea, Troppo mare, Posmodernidad.

Abstract: This article shows an approach to Troppo mare (1984), written by Javier Egea, through the aesthetic and ideological analysis of the poem as an aesthetic verbal object. The importance of the historical context and the textual content itself are intertwined. Egea wrote this work in 1980 as a poetic allegation to historical materialism, but it was not published until 1984, in full swing of Spanish postmodernity. Therefore, the poem, of Marxist content, dealt with a reception problem at the time of its publication due to the fast social and political transformation experienced during the years of the Spanish Transition.
\end{abstract}

Keywords: Poetry, Historical materialism, Javier Egea, Troppo mare, Postmodernity.

\section{INTRODUCCIÓN1}

En el presente artículo se realiza una aproximación a la obra Troppo Mare(1984), del poeta granadino Javier Egea, para confrontarla a las nuevas superestructuras posmodernas que se forman tras el advenimiento de la democracia en España. Nuestro estudio trabaja sobre dos ejes: 1) Troppo mare como un poema que propone una poética basada en la estética del materialismo histórico; 2) la problemática que surge en la recepción de una obra con un contenido y un carácter como Troppo mare en el contexto de la Transición española. En la actualidad existen diversos estudios sobre la figura de Javier Egea, pero ni son tan numerosos como los dedicados a sus compañeros de la Otra Sentimentalidad ni suelen poner en valor Troppo mare, debido al éxito de Paseo de los tristes(1982) — escrito con posterioridad a este pero publicado dos años antes. 
La mayoría de estudios críticos sobre la obra que tratamos toman como punto de partida la condición biográfica de Egea, mientras que nuestra propuesta asume su contexto biográfico, pero confronta el posicionamiento ideológico del poeta frente a las nuevas estructuras democráticas españolas — que permiten que el capitalismo y la posmodernidad impongan sus nuevas prácticas-. Entendemos que Troppo mare es un trabajo en clave poética que reivindica el materialismo histórico frente al ideario pasivo de la posmodernidad. Desde esta perspectiva, Egea se sumerge en el cuestionamiento de la realidad como construcción subjetiva a través del propio lenguaje.

Para entender la importancia de la obra que tratamos resulta necesario realizar una breve aproximación al autor antes de entrar en el análisis del poema y situarlo dentro del campo poético de su época. La figura de Javier Egea está representada en el imaginario poético español como uno de los poetas que forman parte de la Otra Sentimentalidad, movimiento que nace en la ciudad de Granada y que impulsa el profesor Juan Carlos Rodríguez desde sus presupuestos ideológicos. Por ello, el ideario poético del grupo tiene una base marxista, ya que Rodríguez llega a la ciudad andaluza tras ser alumno de Louis Althusser en la Escuela Normal de París, una vez en Granada milita en la célula Gramsci del PCE — donde coincide con Egea-, y desde su magisterio en la universidad adapta las ideas de Althusser — algo innovador entonces en España- proponiendo la concepción del texto literario como un producto ideológico.

La Otra Sentimentalidad tiene un recorrido temporal muy corto, esto se debe, entre otros factores, al contexto histórico y social en el que se desarrolla. Tras la publicación del manifiesto en 1983, el grupo no tarda en comenzar su disolución, ya que, por entonces, Salvador y García Montero cambian de paradigma teórico para trabajar en la normalización de la poesía, lo que supone el olvido de los presupuestos originales de la Otra Sentimentalidad. En ese sentido, Javier Egea se niega a abandonar los postulados marxistas, lo que lo que deja al margen del nuevo camino que están prosiguiendo sus compañeros. Por ello, y unido a la divergencia de propuestas poéticas entre él y el resto del grupo, su importancia dentro del campo poético pierde fuerza según va transcurriendo la década de los 80, hasta que, en 1999 , pone fin a su vida cuando a efectos prácticos ya se encontraba en el olvido popular. La construcción histórica que subyace al relato de la producción de Egea parece omitir en cierto sentido la verdadera confrontación que se encuentra en su poética - por lo menos en aquella a partir de Troppo Mare-, que no es otra que la tensión entre la poesía como herramienta social contra la nueva ideología posmoderna. La verdad material perseguida por la Otra Sentimentalidad se contrapone con la "realidad" que manifiesta la poética de la experiencia.

En este periodo existe una tendencia a enlazar los movimientos de la Otra Sentimentalidad y de la poesía de la experiencia. Ejemplo de lo anterior lo podemos encontrar en la sustitución del adjetivo "Otra" por "Nueva" Sentimentalidad, que propone buena parte de la crítica literaria española con intención de darle una continuidad artificial al movimiento granadino y aumentar así la nómina de autores adscritos a él (Hernández García, 2010, p. 74). Esta tendencia reconoce a Egea como parte originaría de la poesía de la experiencia, algo que Felipe Alcaraz niega con contundencia al asumir que esta es un producto propio de la socialdemocracia algo que en distintas ocasiones afirman de manera directa, o indirecta, Salvador y García Montero- (2010, pp. 67-68):

La poesía de la experiencia no es un afluente de la Otra Sentimentalidad. Son otras aguas. La poesía de la experiencia es el reflejo más exacto de la "normalización" de los años posteriores. No es siquiera una "táctica" de lo que sería una estrategia, la Otra Sentimentalidad, para conseguir ser más útiles, más eficaces en la lucha a favor de una modernidad progresista.

La aparición de la Otra Sentimentalidad supone para la tradición poética española la piedra angular sobre la que poder construir un nuevo sistema basado en una estructura adaptada a los nuevos tiempos democráticos y capitalistas. Aunque los inicios de la propuesta de los poetas de Granada tienen sus bases teóricas en el ideario marxista, esta no tarda en transformarse en un producto mucho más sencillo y acorde a la ideología dominante. Las nuevas superestructuras posmodernas arribadas con la democracia hacen envejecer con una 
gran rapidez la propuesta originaria de la Otra Sentimentalidad, circunstancia que Javier Egea no asume y, de alguna manera, provoca que el poeta "haga la guerra por su cuenta".

Debido a su edad, la poética de Egea se fragua con anterioridad a la Otra Sentimentalidad, a diferencia de los autores más jóvenes - como sí es el caso de García Montero—, ya que inicia su carrera lírica en el ambiente universitario granadino de finales de los 60. Por entonces colabora con la revista Poesía 70, publicación dirigida por Juan de Loxa y que tiene su origen en el programa de radio homónimo que él mismo conduce. En 1972 gana el accésit del premio Federico García Lorca, certamen que convoca la Universidad de Granada. Así, dos años después, la editorial de la universidad publica la obra premiada con el nombre de Serena luz del viento(1974). En este periodo la poética de Egea comienza a mostrar signos de una influencia marxista, quedando patente en su producción la aprehensión de una consciencia de clase y la asimilación de nuevos códigos formales y culturales (Hernández García, 2010). Esta transformación poética toma cuerpo cuando, de nuevo, la Universidad de Granada decide publicar su siguiente trabajo, titulado $A$ boca de parir(Egea, 1976). En estos años, conoce a Juan Carlos Rodríguez, lo que será una relación fundamental en el desarrollo de su poética. En 1980 Javier Egea se desplaza hasta la Isleta del Moro (Almería), donde pasa unas semanas, y de la que vuelve con gran parte escrita de Troppo mare. Meses después, el poeta granadino acude al Palacio de la Madraza (Granada) para realizar una lectura poética sobre aquella obra. La presentación corre a cargo de Juan Carlos Rodríguez (cit. en Egea, 1984b, pp. 12-13) —el texto del profesor se utiliza como prólogo de Troppo mare cuando se publica en 1984-, y en un momento dado alaba a Egea en los siguientes términos:

\begin{abstract}
Por eso los poemas de Javier Egea no nos hablan sino de ese proceso de transformación. Por eso hablan siempre de la muerte, pero para transformarla en vida. Al final de ese duro, penoso, larguísimo proceso de transformación, de ruptura (biográfica, ideológica, poética y política), Javier Egea se encerró en un pequeño pueblo de Almería, la Isleta del Moro, y, al regresar, me enseñó un largo poema, Troppo Mare. Lo leí y quedé estupefacto. Hacía meses que no nos veíamos. Comprendí que mi entrañable amigo, mi antiguo compañero de la Agrupación Antonio Gramsci, se había convertido en el poeta que él siempre quiso ser. Había roto Javier Egea al fin con la cárcel del rito y el mito de la palabra poética y había dado el salto a la otra orilla: la poesía como una nueva práctica, como práctica ideológica.
\end{abstract}

\title{
Troppo MARE, EL ÚlTiMo REFUgio CONTRA LA POSMODERNIDAD
}

La poética de Javier Egea tiene un punto de inflexión en su trayectoria. Troppo Mare resulta una obra que supera la mera declaración de intenciones. En 1980, Egea cumple veintiocho años en un momento en el que en España acaece una transformación social y política de gran intensidad. La socialdemocracia se instala dentro de las estructuras del Estado y las prácticas culturales propias del nuevo periodo posmoderno se normalizan. Frente a ello, Egea produce un poemario que se sita en los márgenes de los nuevos tiempos y se enfrenta a la España democrática con una propuesta estética que desgrana al sujeto individual dentro del colectivo.

En Troppo mare los recursos transtexuales se configuran como ejes discursivos que orientan la dirección del texto como objeto verbal estético para ubicarlo frente a la norma capitalista imperante. Este manifiesta su condición subversiva desde la elección del título, al utilizar a modo de homenaje las primeras palabras del poema "Gente Spaesata" (1998, p. 13), que se publica originalmente en el poemario Lavorare stanca(1936) del poeta italiano Cesare Pavese - "Troppo mare. Ne abbiamo veduto abbastanza di mare. / Alla sera, che l'acqua si stende slavata / e sfumata nel nulla, l'amico la fissa e io fisso l'amico e non parla nessuno"- Dicha elección no parece mera casualidad, ya que la obra de Pavese se publica en el mismo año que estalla la Guerra Civil española. Si el título indica la condición ideológica de la obra al citar a un autor que milita durante parte de su vida en el Partido Comunista Italiano, esta manifestación se consolida al utilizar para la apertura de la primera sección del poema los versos de otro poeta transalpino que también milita en el PCI hasta su expulsión, como es Pier Paolo Pasolini - autor que tiene gran peso entre los jóvenes poetas de la Otra Sentimentalidad-. Troppo mare abre con la frase "No es de mayo este aire impuro", al igual que Pasolini 
comienza el canto I de su obra Las cenizas de Gramsci(1957). De esta forma, antes de que el lector pueda comenzar la lectura de Troppo mare se debe encontrar con varios elementos transtextuales que enlazan el contenido con referencias marxistas. Estas referencias no son las únicas, ya que cada sección tiene un título con carga intertextual:

1" “Troppo Mare", título elegido por la referencia a Pavese que comentamos en el párrafo anterior y que tiene como cita introductoria el verso de Pasolini.

2a "Rosetta", en este apartado Egea utiliza los versos de Miguel Hernández: "Besarse a la luna, / mujer, es besarnos / en toda la muerte"

3a "El viajero", abre con la cita de Garcilaso “... solo, desamparado, / ciego, sin lumbre, en cárcel tenebrosa”. 4a "El estrago", en esta ocasión la cita de apertura - "De mi vida dudosa, estrago cierto..." - se atribuye en las primeras ediciones a García de la Vega, cuando en realidad es de Vicente García de la Huerta (Egea, 1984b, p. 49)

5a "Coram Pópulo", esta sección comienza con los versos de García Lorca "Entre los juncos y la baja tarde, / qué raro que me llame Federico”.

El libro cierra con "Coda", que, aunque a diferencia de las partes antecesoras, no viene introducida por ninguna mención textual, sí que el propio nombre del apartado es una alusión al lenguaje musical, ya que hace referencia al movimiento que sirve de epílogo en una composición de este tipo.

Desde una perspectiva global, Troppo mare representa un canto a la derrota personal — desde la experiencia de Egea- y un canto al fracaso colectivo proyectado en el ocaso de la causa marxista ante la nueva democracia y la posmodernidad. La tendencia lúgubre del texto propone un paisaje desolado, donde el mar dispone de una fuerte presencia -incluso cuando no es nombrado directamente, el paisaje descrito lo evoca indirectamente - y donde la mirada del yo y del otro se entrecruzan, otorgándole a los ojos un valor simbólico muy importante dentro de la obra. La concepción de lo visto y de la construcción del relato que compone la memoria/historia conforman dos de los pilares fundamentales del discurso subyacente al poema.

La personificación del fracaso toma forma en el texto a través de "La Nube". La Nube aparece por primera vez en la sección primera, en los últimos versos del canto I y en los primeros del canto II, y Egea alude a ella como una especie de elemento capaz de destruir todo a su paso. No se refiere únicamente a una destrucción personal - la voz poética se presenta como alguien que parece ser víctima de una intensa melancolía-, sino también a la destrucción histórica —en lo que parece una evidente alusión a Lyotard (1979)—: "Tanto mar y de golpe, / tanta historia y vencida, / ya corazón mojado sobre el abra, / ya mensaje dormido, preterido, / en la Bahía de los Genoveses" (Egea, 1984b, p. 19).

El tiempo resulta una constante en la obra. La fusión entre presente y pasado posiciona al discurso en la voz del inconsciente colectivo. Egea dirige su alegato hacia la necesidad de identificar los engranajes del comportamiento individual proveniente de la colectividad social, pero este intento de desenmascarar al inconsciente no está exento de contradicciones. En este sentido, Mariel Gutiérrez (2014, p. 123) comenta lo siguiente:

La creatividad encierra una nueva realidad, en íntima relación con el inconsciente. A la vez que echa luz sobre el deseo inconsciente, también lo enmascara. Constituye un puente entre el proceso primario y el secundario y conjuga percepciones, representaciones, fantasías y pensamientos. Estos procesos se elaboran con la metáfora enlazada al desplazamiento metonímico.

En Troppo mare la voz poética ocupa el lugar común para manifestar una derrota colectiva donde la línea temporal se rompe con la intención de mostrar un espacio descrito como un naufragio, pero no únicamente como un naufragio marítimo, sino también como un naufragio vital, donde aparece de manera recurrente La Nube, que es un elemento que amenaza la estabilidad del texto. El propio yo poético se proyecta sobre una historia donde su posición se confunde con la del otro. Sin embargo, una de las constantes del libro 
la encontramos en la tensión existente entre la duda de la propia subjetividad y el lenguaje dado (Bellón Aguilera, 2007, p. 14). Esta confrontación sitúa la problemática existencial en términos althussianos, es decir, se concibe la historia como un proceso impersonal — que carece de sujeto individual - y que no tiene una motivación específica. Por tanto, la articulación de la historia se encuentra en la lucha de clases sociales. Por ello, en el momento de creación de Troppo mare parece que el poeta granadino siente que la clase trabajadora - con la que él se identifica, a pesar de sus orígenes acomodados- está siendo derrotada por el discurso de la Transición sin ni siquiera presentar resistencia. Mientras que en la Unión Soviética aún se mantiene el discurso utópico marxista y en China el PCC intenta dejar atrás la Revolución Cultural para mantener el sistema comunista, en España los movimientos sociales y de izquierdas acatan los términos democráticos surgidos en el 78 y abandonan la radicalidad previa a la democracia.

$\mathrm{Si}$ atendemos al posicionamiento del yo poético dentro del poema, este transmuta de perspectiva ("nosotros", "él”) según el texto va cambiando de sección. En cierto modo, Egea propone una concepción del inconsciente colectivo como un campo de batalla donde solo se puede vencer a través del descubrimiento público de la ideología dominante. El poeta manifiesta en Troppo mare la necesidad de exponer el funcionamiento de los modos de producción que sirven a las clases dominantes con la esperanza de que el conocimiento una al colectivo. Pero la derrota se impone como inevitable, Egea evidencia un pensamiento inocente frente al voraz comportamiento posmoderno, los tiempos de la clandestinidad son ya pretéritos, un pasado reciente, pero un pasado que no volverá. A pesar de ello, realiza un canto colectivo llamando a la subversión de la norma y alentando a la confrontación contra la dominación ideológica posmoderna. Para ello, el poeta granadino disuelve el sujeto individual en el otro y lo proyecta como una unidad superviviente. En esta línea, Martín Puya (2011, p. 95) opina lo siguiente sobre la alternancia de voces y la proyección de la otredad en Troppo mare:

\begin{abstract}
Al mismo tiempo, la multiplicidad de voces responde al deseo de identificación del sujeto con los otros, lo que conducirá al poeta a decantarse en las secciones finales por el paso del "yo" al "nosotros", de tal modo que este individuo que antes hablaba de sí mismo en tercera persona, como si fuera otro, cuando habla en primera persona habla también de los otros; ese mismo individuo, universal (puesto que el asedio ideológico y vital es el mismo para todos), aparece ejemplificado en la figura del viajero Miguel, en la que es la sección central del libro, vencido en su búsqueda por alcanzar la (otra) luz, y presente en la historia y en la memoria, y por ello merecedor de la posible victoria futura. El estrago individual sufrido y atravesado por el "yo" le permite conquistar la consciencia de colectividad del "nosotros".
\end{abstract}

En Troppo mare existe cierta semejanza con La Odisea en tanto que el yo poético realiza una translación errática en diferentes escenarios y etapas, que corresponden a las diversas secciones que componen la obra. Durante esta travesía el protagonista no se enfrenta contra la ira de ningún dios ni contra la furia de cíclope alguno, sino contra lo real como algo aceptado. Las secciones del libro marcan los estadios del viaje hasta llegar al culmen que es la Coda. En cierta manera, la estética que Egea plantea se puede entender como un todo, compuesto por una serie de elementos interrelacionados entre ellos: la historia, la lucha de clases, la negación de lo dado, lo individual y lo colectivo, lo personal y lo global, el fracaso y la esperanza de la vida. Cada parte encaja en los engranajes del poema para montar el mecanismo que lo estructura, de manera que la práctica poética se propone como herramienta social. Según se desprende de los versos de Egea, el sujeto individual carece de sentido sin la colectividad, y solo la colectividad puede batallar la lucha de clases.

La primera sección de Troppo mare realiza la presentación del poema, por un lado, la voz lírica detalla la escena de naufragio, describiendo a una nave despedazada en la escollera. Por el otro, un naufragio social: "Tanto mar y de golpe, / tanta historia y vencida" (Egea, 1984b, p. 19). Así, el fracaso se representa a través del accidente naval, pero en los últimos versos se alude a otro tópico recurrente en la obra, la memoria como eje discursivo del presente: "inútiles las manos que desde las palmeras / pretenden el abrazo de un horizonte roto/ a donde tu recuerdo se avecina” (p. 20). El tiempo pretérito se confunde con lo presente, en un intento por parte del poeta de mostrar el eje temporal como un concepto esférico donde el individuo no tiene capacidad de avanzar más allá de su propio recorrido vital. 
Egea concibe la necesidad de proyectarse en el otro para comprender la realidad histórica, pero en su búsqueda necesita también desmarañar el entramado de la subjetividad. Por ello, la reflexión de los acontecimientos y el recurso de la prosopopeya resultan habituales durante toda la obra, con una especial intensidad en "Rosetta", capítulo donde la visión se impone como eje discursivo, a la vez que elabora un juego semántico que expone la tensión entre la construcción del discurso histórico y el inconsciente: "que no supo mirar, mas le miraban" (p. 33), "y unos ojos de mármol vigilaban sus ojos" (p. 33), "la soledad miraba” (p. 33). Comienza esta segunda sección con una constante alusión a la vista, que tiene numerosas referencias posteriores a lo largo del poema, vemos aquí algunos ejemplos que aparecen en páginas ulteriores: "me fue poniendo al día los ojos interiores" (p. 54), "Las historias se cuentan con los ojos del frío" (p. 63). La visión toma cuerpo representando la subjetividad. La construcción histórica desde el yo carece de valor dentro de los términos althusserianos, ya que el hombre no tiene cabida en la propia historia. Así, el texto sugiere la necesidad de reflexionar sobra la carga ideológica del inconsciente para liberarse de la subjetividad dada.

En la tercera sección, "El viajero", la voz poética abandona la primera persona para narrar la historia de un viajero llamado Miguel. La estructuración de la sección indica al lector que el protagonista de los versos se enfrenta en un tiempo pasado a una agresión, como se puede apreciar en el primer verso del canto I: "El asedio tan largo, y los pertrechos escasos/ y ese frío inhumano y sin embargo suyo" (p. 41). El inicio del canto nos señala que la resistencia no está preparada para aguantar mucho más ese asedio simbólico. El poeta plantea en el campo vital una lucha perdida contra un enemigo "inhumano", pero el asedio termina por romperse cuando el viajero consigue superarlo y huir lejos de una ciudad "Ingrata,/ absurda,/ enorme" (p. 42). La ciudad se concibe como un núcleo burgués que emana oscuridad y negatividad, así, mientras que poco tiempo después de la publicación de Troppo mare los poetas de la experiencia transforman el entorno urbano en el espacio donde se desarrolla su poética, Egea otorga a los espacios naturales - marítimos en este casoun valor positivo donde el yo poético se detiene para ejecutar el pensamiento crítico.

En esta sección, la voz poética sufre una especie de transmutación continua, en un momento dado pasa de la tercera persona del singular a la primera en sus dos formas. Esta traslación del eje discursivo propone al lector la idea de una colectividad necesaria para luchar contra el "frío". Pero sobre toda esta contienda se entrevé otra la vez la historia y la necesidad categórica de superar el inconsciente ideológico para producir una poesía capaz de enfrentarse a la imperante burguesa: "No es de ahora esta luz. / No son nuevos los aires" (p. 44). El último texto muestra la muerte de Miguel donde se citan de nuevo dos elementos recurrentes en Troppo mare: la luz y los ojos. Dichos elementos representan sendas sobre los que discurre la propuesta subversiva de Egea, lo posible pasa porque la luz y los ojos —o la vista - transcurran sobre un mismo punto. De esta manera el individuo puede descubrir los entramados de la realidad y actuar conforme a ello.

En "El estrago" podemos encontrar el apartado más duro de toda la obra. La voz poética asume su propia consciencia y, en ese momento, conoce su fracaso en una suerte de engranaje atemporal, ya que la derrota tiene una naturaleza histórica, como así lo demuestra el juego de tiempos verbales de la sección. El sujeto individual toma forma frente al espejo — "Habré de verme aún una mañana más / a pesar de saber de memoria estos ojos" (p. 51) - siendo capaz de verse a sí mismo gracias a la iluminación — "reconocido en esta violeta de la luz / que me hiere y me canta. / Reconocido, sí, en este laberinto de pavesas" (p. 52)—. La consciencia se sitúa y reconoce su posición dentro de los medios de producción - "Y he llevado mis pasos al mercado mis pasos y mis manos / hasta donde me llega la memoria” (p. 52) - Egea lacera al protagonista del poema en cualquiera de sus versiones - señalándolo como un perdedor que está obligado a conocer su condición para revertirla.

Según van sucediéndose los versos la vista toma gran importancia como un sentido vital. El simbolismo de los ojos (citados como miembros exteriores e interiores) se alinea con la alegoría de la caverna de Platón, es decir, la visión resulta la causa de la confusión. Frente a los ojos, solo la luz puede iluminar la verdad, así en el poema esta representa el conocimiento y se impone sobre la "memoria" (p. 56), la "soledad" (p. 56) y la "historia" (p. 57). Ante ella está la ceguera — "Será que tuve suerte de no quedarme ciego" (p. 53) — y el 
frío, que ejercen de contraposición y gobiernan el paisaje donde se desarrolla las diferentes secciones. El poeta utiliza la ceguera como condición irreversible, ya que la luz no puede ser captada por aquel que no ve, aunque disponga de ojos, en clara alusión a la imposibilidad de reconocer al inconsciente.

En la última sección -omitimos como tal "la Coda" al considerarla un texto conclusivo-, "Coram Pópulo”, Egea enarbola la bandera de la Otra Sentimentalidad al proyectar el yo poético desde una perspectiva sentimental colectiva. Así, el canto I comienza con "Lo que puedo contaros / es todo lo que sé sobre el dolor / y eso nunca se inventa" (p. 63) para confrontar el discurso personal contra el discurso histórico: "Las historias se cuentan con los ojos del frío" (p. 63). La propuesta está sobre la mesa, la ruptura del discurso poético hegemónico a favor de la búsqueda de una poesía materialista histórica. El problema que surge del choque formal se encuentra en la viabilidad de unos presupuestos teóricos que Egea no parece capaz de definir completamente y en los que, a pesar de perseguir unos objetivos que disponen de un espíritu rompedor y subversivo, el poeta no consigue superar la condición de derrotado.

Al tratar la última sección resulta inevitable recordar la cita atribuida a Rainer María Rilke que afirma que "La infancia es la verdadera patria del hombre", o aquella de Leopoldo María Panero (cit. en Chávarri, 1976) en la que dice que "En la infancia vivimos, y después sobrevivimos". Javier Egea muestra en "Coram Pópulo" varios pasajes de un tiempo pretérito que hablan sobre recuerdos de una niñez. Debemos recordar que el poeta de Granada concibe el poema como un artificio, y por tanto lo que manifiesta no es verídico. Por ello, el pasaje de esta última sección transmite un sentimentalismo que funciona a través de la imagen de la "casa”, "el amor" y "la madre". El escenario se construye con imágenes quebradas y en ruinas donde el frío se expande por todos los versos — “éramos ya cercanos de la muerte / brotes de frío” (Egea, 1984a, p. 64), "Era todo erial y itanto frío! (p. 64) - y se contraponen con el amor que se transmite una -otra- escena de derrota, como es la muerte de la madre de la voz poética - "No era posible, tú, la de todos los días, / de pronto entre algodones acunada. / A través del cristal / sobre sábanas blancas, / están dispuesto los claveles" (p. 68), "Por no saber tu vientre de madre detenido / yo no quise mirar bajo las sábanas" (p. 69)—. "Coram Pópulo" establece un nexo de unión entre el espacio privado y lo público, es decir, entre lo individual y lo colectivo: El compromiso de los derrotados frente al frío que los envuelve.

La travesía que Javier Egea comienza con su llegada a la Isleta del Moro traspasa los términos poéticos y asimila elementos musicales (Dvorakova, 2013b), de esta forma Troppo mare solo puede acabar con una coda, que en cierta manera, rompe con el discurso derrotista de las secciones precedentes. La coda toma la función de resumen a la vez que vuelve a servir de declaración de intenciones en defensa del pensamiento marxista. Egea titula su epílogo final como "Leer El capital" —alude de esta forma a la obra homónima de Althusser - y comienza con estos versos: "Hipócrita lector, hermano, camarada, / hoy me atrevo a contar tus años y los míos: / mira tanta ceniza / como una herencia gris entre las manos, / mira sangre o asombro tu corazón y el mío tiritando / sobre el extraño hedor de las palabras muertas" (Egea, 1984a, p. 73). La primera estrofa resulta desgarradora, la adjetivación del lector a la par que la asunción de este como compañero reflejan las heridas que el poeta aprecia en el pensamiento marxista tras la llegada de la socialdemocracia. El hecho de que Egea mencione las cenizas entre las manos tiene un valor simbólico, ya que la frase de Pasolini con la que abre la primera sección de Troppo mare está extraída de la obra Las cenizas de Gramsci, que a su vez es una referencia que usa el poeta italiano para tratar el mito del Ave Fénix. La posibilidad de levantarse de la derrota es un hecho, aunque, si bien durante toda la obra se evoca a la muerte, a la ruina y a la derrota histórica, se descubre un mensaje vital y positivo al finalizar el poemario: "Hoy solo sé que existo y amanece" (p. 74). La coda representa un cierre, pero también se impone como un nexo de unión y un aviso: cada sección del poema no puede entenderse fuera del contexto del resto de secciones. 


\section{Últimas CONSIDERACIONES SOBRE TROPPO MARE}

Cuando Troppo Mare se publica en 1984 — cuatro años después de su conclusión y dos de Paseo de los tristes(1982) - la obra se enfrenta a varios problemas de recepción. El principal de ellos se encuentra en el hecho de que es un poema que representa el ideario de la Otra Sentimentalidad, y en el momento de su publicación el movimiento está en pleno proceso de disolución. A esto hay que añadir que la buena acogida que tuvo Paseo de los tristes - que consigue el Premio Hispanoamericano de poesía Juan Ramón Jiménezen cierta forma eclipsa a Troppo mare, centrando en esta obra los focos de la mayoría de estudios existentes sobre Egea - aunque parece que en los últimosños esta tendencia se está revirtiendo-. En lo que refiere al contexto histórico y social la publicación del poema llega tarde, Felipe González gana las elecciones de 1982 y los españoles abrazan de pleno la socialdemocracia, mientras que el PCE se encuentra en un proceso de ruptura, ya que en el lapso de tiempo entre 1978 a 1984, el partido sufre una sangría en nmero de militantes y en escisiones que merman su poder y anulan el discurso marxista como alternativa. Para más inri para la causa marxista, la Unión Soviética ya muestra síntomas de agotamiento vital.

La propuesta de Egea de considerar el objeto verbal estético como una herramienta de resistencia colectiva contra los poderes hegemónicos, luchando de esta forma contra el inconsciente y la propia concepción de historia y subjetividad, no tiene un gran impacto en el momento de su publicación - a pesar de conseguir el Premio literario Antonio González de Lama-. Por entonces, la tendencia dominante dentro del campo poético se localiza en la normalización que llevan a cabo García Montero y Salvador, y que da lugar a la poesía de la experiencia. De esta forma, la producción lírica basada en el materialismo histórico no tiene cabida dentro de estos presupuestos poéticos.

La estética de Troppo mare está construida sobre valores marxistas. Por ello, Egea la concibe a sabiendas de que la propuesta se iba a instalar en los márgenes del discurso poético español — probablemente lo que no imagina Egea en 1980 es que en 1984 se encontraría en una posición tan solitaria en esos márgenes-. La principal problemática que encuentra el poema es que el lector español de 1984 no está preparado para aceptar los términos estéticos que se proponen en la obra, la interpretación que este puede dar al texto se alejan del mensaje original subversivo. En este sentido, en referencia al juego de significado y significante de un poema, Terry Eagleton (2007, p. 73) opina lo siguiente:

Atender a la naturaleza sistémica de los poemas no debería impedirnos advertir que también constituyen ejemplos de juego. Esta es una manera más de desviarse de una civilización obsesionada por lo económicamente rentable. Meramente por existir, la poesía cumple una función utópica, mostrando una forma de vida no tan subyugada al trabajo, a la coerción y a la obligación. La poesía es una forma superior de balbuceo. Los más elevados ejercicios de la imaginación, como hemos visto, rayan en las más regresivas fantasías. Un poema es un recreo semiótico, en el cual el significante es dispensado de sus adustos esfuerzos comunicativos y pueden divertirse sin abochornase. Libre ya de un matrimonio sin amor con un único significado, el significante puede ir de flor en flor, mostrándose promiscuo, retozar impúdicamente con otros significantes también libres de compromiso. Si los guardianes de la moral convencional comprendieran lo indecente que es la poesía, dejarían inmediatamente de inscribir poemas en sus tumbas.

El dilema al que nos enfrentamos al tratar Troppo mare se encuentra en el cuestionamiento crítico de si el lector español de 1984 puede entender las connotaciones marxistas del poema, o si bien, la lectura de la obra desde una perspectiva posmoderna no tiene profundidad para lograr penetrar en los códigos ideológicos del texto. He aquí el caballo de batalla de Egea, la lucha contra la cultura posmoderna -aunque probablemente en el momento de su producción los términos sobre los que construye su discurso identifiquen al capitalismo y a la burguesía como los "dominantes", cuando en realidad las prácticas posmodernas son las que cambian el paradigma cultural español, aletargando el pensamiento crítico y anulando la consciencia de clase- - Si no hay consciencia de clase, la colectividad desaparece transmutando en masa, de esta forma, las prácticas ligadas a la posmodernidad transforman todo lo posible en bien de consumo. Así, la sociedad se vuelve "líquida" (en 
términos de Bauman) y la poesía, como producción social (aludimos así a la teoría del reflejo de Lukács), tiende a las formas sencillas y ligeras, lejos de los presupuestos de la Otra Sentimentalidad.

La propuesta estética de Javier Egea en Troppo mare manifiesta la poesía como objeto verbal estético que debe comprometerse y servir de confrontación ante el poder dominante, enfrentándose sin miramientos contra la poesía burguesa. Uno de los logros del poeta granadino se halla en la unión del espacio privado y el espacio público. De esta manera, se logra conseguir un "nosotros" frente a un "ellos". El discurso del materialismo histórico tiene como objetivo romper con la poesía burguesa, analizar la subjetividad como algo dado a través de la ideología, y desmarañar en tanto sea posible al inconsciente. Sobre lo pretensioso de la propuesta, Paula Dvorakova opina lo siguiente (2013a, p. 58):

En este sentido, si quisiéramos pensar en la posibilidad de una escritura materialista basada en una ruptura total y completa, probablemente lo único que haríamos sería considerar la ideología como algo mucho más plano y más transparente de lo que realmente es. Hasta podríamos volver a algunos planteamientos que en el fondo son esencialistas y conservadores, a pesar de pretender justamente lo contrario. Construiríamos la imagen de un poeta capaz de cambiar el mundo. Pero el problema es que ni la ideología es tan plana como para poder resolver sus mecanismos en una lucha (ideológica o literaria), ni una ruptura puede llegar a ser definitiva. Por lo tanto, si existe realmente la poesía materialista, llevará dentro de sí siempre una profunda conciencia de la derrota.

Con independencia de que el objetivo contra el que dirigir el discurso sea el capitalismo en cualquiera de sus expresiones o la posmodernidad como ese monstruo que lo va devorando todo a su paso, Egea no se limita a expresar su condición ideológica, sino que proyecta la palabra como el último resquicio de resistencia, donde el sujeto individual puede tomar consciencia.

El sueño de la poesía del materialismo histórico comienza en las reuniones de la Otra Sentimentalidad, pero finaliza cuando Javier Egea queda aislado en el campo poético. En cierta manera, y haciendo uso de las diferentes acepciones de la que dispone la palabra derrota, podemos afirmar que el poeta granadino elige la suya propia y se enfrenta a ella hasta las últimas consecuencias. Troppo mare llega al mercado demasiado tarde, la estética marxista ya está herida de muerte en 1984, y el discurso de la lucha de clases no tiene cabida en el nuevo paradigma posmoderno, pero incluso así, Egea se niega a abandonar la senda que comienza con la Otra Sentimentalidad para adaptar su poética a la nueva poesía de la experiencia.

\section{REFERENCIAS}

Alcaraz Masats, F. (2010). Javier Egea y el desprestigio de la realidad. Revista de crítica literaria marxista, 3, 62-68.

Bellón Aguilera, J. L. (2007). Todo modo: Hechos y palabras en la poesía de la experiencia. Bulletin of Hispanic Studies, 84(6), 797-820.

Chávarri, J. (1976). El desencanto. España: Elías Querejeta Producciones Cinematográficas S.L.

Dvorakova, P. (2013a). Las paradojas del «otro romanticismo»: La intimidad como resistencia en la poesía de Javier Egea. Impossibilia, 5(Abril), 47-62.

Dvorakova, P. (2013b). Pasos de un caminante solitario: tres claves de la poesía de Javier Egea. Álabe, 7(Junio), 1-18. Recuperado de http://repositorio.ual.es/bitstream/handle/10835/5197/170-766-1-PB.pdf?sequence=1

Eagleton, T. (2007). Cómo leer un poema (2016. ${ }^{\mathrm{a}}$ ed.). Oxford: Akal.

Egea, J. (1974). Serena luz del viento. Granada: Universidad de Granada.

Egea, J. (1976). A boca de parir. Granada: Universidad de Granada.

Egea, J. (1982). Paseo de los tristes. Huelva: Instituto de Estudios Onubenses.

Egea, J. (1984a). Troppo mare. León: Diputación provincial.

Egea, J. (1984b). Troppo mare (2017. a ed.). Granada: Esdrújula.

Gutiérrrez, M. (2014). Revista uruguaya de Psicoanálisis. Creación artística y psicoanálisis, 118, 122-135.

Hernández García, J. A. (2010). Con esperanza y convencimiento. Revista de crítica literaria marxista, 3, 69-89. 
Lyotard, J.-F. (1979). La condición posmoderna. Informe sobre el saber (1991.a ed.). Buenos aires: R.E.I. Argentina. Recuperado de http://cmap.javeriana.edu.co/servlet/SBReadResourceServlet?rid=1KBWV3GHX-14QHSD F-321

Martín Puya, A. I. (2011). Troppo Mare: la búsqueda de un oasis de tierra en el desierto marino. Impossibilia, 1, 88-123. Pasolini, P. P. (1957). Le ceneri di Gramsci. Milán: Garzanti.

Pavese, C. (1936). Lavorare stanca. Florencia: Solaria.

Pavese, C. (1998). Poesie. (M. Masoero, Ed.). Turín: Einaudi.

\section{Notas}

1 Este artículo se halla vinculado al Proyecto de Investigación del Plan Estatal "Poéticas de la Transición (1973-1982)" Ref. FFI2017-84759-P (AEI/FEDER, UE). 